\title{
PENGKAJIAN RESEP SECARA ADMINISTRATIF BERDASARKAN PERATURAN MENTERI KESEHATAN RI NO 35 TAHUN 2014 PADA RESEP DOKTER SPESIALIS KANDUNGAN DI APOTEK STHIRA DHIPA
}

\author{
(RECIPES FOR ADMINISTRATIVE ASSESSMENT BASED ON REGULATION OF THE \\ MINISTER OF HEALTH RI NO 35 YEAR 2014 ON OBSTETRICIANS MEDICAL \\ PRESCRIPTION IN PHARMACIES STHIRA DHIPA)
}

\author{
FITRIA MEGAWATI ${ }^{\bullet}$, PUGUH SANTOSO $^{1}$ \\ ${ }^{1}$ Akademi Farmasi Saraswati Denpasar, Jalan Kamboja no. 11A, Denpasar
}

\begin{abstract}
Abstrak: Dalam alur pelayanan resep, apoteker wajib melakukan skrining resep yang meliputi skrining admninstratif, kesesuaian farmasetis, dan kesesuian klinis untuk menjamin legalitas suatu resep dan meminimalkan kesalahan pengobatan. Aspek admnistratif resep dipilih karena merupakan skrining awal pada saat resep dilayani di apotek karena mencakup seluruh informasi di dalam resep yang berkaitan dengan kejelasaan tulisan obat, keabsahan resep, dan kejelasan informasi di dalam resep. Akibat ketidaklengkapan admnistratif resep bisa berdampak buruk bagi pasien, merupakan tahap skrining awal guna mencegah adanya medication error. Penelitian ini bertujuan untuk mengetahui kelengkapan administratif resep dokter spesialis kandungan memenuhi ketentuan kelengkapan resep menurut PMK No 35 tahun 2014. Penelitian yang dilakukan bersifat deskriptif dan pengambilan data dilakukan secara retrospektif. Pengambilan data dilakukan dengan mengamati seluruh resep yang masuk selama periode Januari-Mei 2015 yang ditulis oleh dokter spesialis kandungan. Dilakukan skrining administratif terhadap 350 resep dokter spesialis kandungan dengan mengisi tabel pengambilan data (check list), sesuai dengan aspek kelengkapan resep yang ditinjau. Data yang di peroleh akan dikumpulkan dan disajikan secara deskriptif. Dari hasil penelitian menunjukan persentase kejadian ketidaklengkapan resep di apotek Sthira Dhipa yaitu umur pasien 62\%, jenis kelamin pasien 100\%, berat badan pasien $100 \%$, SIP dokter $100 \%$, alamat pasien 99,43\%, paraf dokter 19\%, serta tanggal resep 1\%, nama pasien, nama dokter, alamat dokter, serta no telepon dokter yang dituliskan oleh dokter telah mencapai $100 \%$. Kelengkapan resep dokter spesialis kandungan belum memenuhi ketentuan kelengkapan admnistratif resep menurut PMK No 35 tahun 2014.
\end{abstract}

Kata Kunci: apotek sthira dhipa, kelengkapan administratif, resep dokter spesialis kandungan.

Abstract: In the service flow prescriptions, pharmacists are required to conduct screening recipes that include the administrative screening, pharmaceutical suitability, and clinical suitability to ensure the legality of a prescription and minimizing medication errors. Administrative aspects recipes have been selected for an initial screening at the time of the recipes served at the pharmacy because it covers all the information on the prescription related medications writing, the validity of prescriptions, and clarity of the information on the prescription. Due to lack prescription, administrative accessories can be bad for the patient, which is stage in order to prevent medication errors. This study aims to determine the administrative completeness obstetrician prescription comply completeness recipes by PMK No. 35 in 2014. The research is descriptive and retrospective data collection. Data collection was performed by observing the entire recipe entered during the period from January to May 2015 was written by an obstetrician. Administrative screening of the 350 recipes obstetrician by filling table data capture (check list), in accordance with aspects of the completeness of the recipes are reviewed. The data obtained will be collected and the data are presented descriptively. From the research results show the percentage of prescriptions in pharmacies Sthira Dhipa incompleteness is $62 \%$ of the patient's age, gender of the patient $100 \%, 100 \%$ weight of the patient, the SIP doctor $100 \%$, patient's addresses $99.43 \%, 19 \%$ physicians initials, and the date the prescription $1 \%$, patient name, doctor's name, address of the doctor, and the doctor's telephone number written by doctors has reached $100 \%$. Completeness prescription obstetrician not fulfilled the requirement of completeness administrative recipes by PMK No. 35 in 2014.

Keywords: prescription obstetrician, pharmacies sthira dhipa, administrative requirement

\footnotetext{
•email korespondensi: f.mega83@gmail.com
} 


\section{PENDAHULUAN}

Dalam pelayanan kesehatan obat merupakan komponen yang penting karena diperlukan dalam sebagian besar upaya kesehatan baik upaya preventif, promotif, kuratif dan rehabilitatif. Pesatnya perkembangan Ilmu Pengetahuan dan Teknologi (IPTEK) juga berpengaruh terhadap peningkatan penelitian di bidang farmasi.

Pasien dengan masalah kesehatan tertentu melakukan pemeriksaan ke dokter, biasanya diberi pilihan terapi yang akan dijalankan. Terapi obat sejauh ini merupakan yang paling sering dipilih. Pada banyak kasus, terapi obat sering melibatkan penulisan resep. Resep merupakan hal terpenting sebelum pasien menerima obat. Dalam alur pelayanan resep, apoteker wajib melakukan skrining resep yang meliputi skrining admninstratif, kesesuaian farmasetis, dan kesesuian klinis untuk menjamin legalitas suatu resep dan meminimalkan kesalahan pengobatan. Resep harus ditulis dengan jelas untuk menghindari salah persepsi antara penulis dengan pembaca resep, kegagalan komunikasi dan salah interpretasi antara dokter dengan apoteker merupakan salah satu faktor kesalahan medikasi (medication error) yang berakibat fatal bagi pasien.

Resep yang baik harus memuat cukup informasi yang memungkinkan ahli farmasi yang bersangkutan mengerti obat apa yang akan diberikan kepada pasien. Namun pada kenyataannya, masih banyak permasalahan yang ditemui dalam peresepan.

Aspek admnistratif resep dipilih karena merupakan skrining awal pada saat resep dilayani di apotek, skrining admnistratif perlu dilakukan karena mencakup seluruh informasi di dalam resep yang berkaitan dengan kejelasaan tulisan obat, keabsahan resep, dan kejelasan informasi di dalam resep. Dalam penulisan resep kelengkapan admnistratif sudah diatur dalam Peraturan Menteri Kesehatan Republik Indonesia Nomor 35 Tahun 2014 Tentang Standar Pelayanan Kefarmasian Di Apotek. Akibat ketidaklengkapan admnistratif resep bisa berdampak buruk bagi pasien, yang merupakan tahap skrining awal guna mencegah adanya medication error.

Permasalahan dalam peresepan merupakan salah satu kejadian medication error. Menurut Surat Keputusan Menteri Kesehatan RI No.1027/MENKES/SK/IX/2004 menyebutkan bahwa medication error adalah kejadian yang merugikan pasien akibat pemakaian obat selama dalam penanganan tenaga kesehatan yang sebetulnya dapat dicegah. Bentuk medication error yang terjadi adalah pada fase prescribing (error terjadi pada penulisan resep) yaitu kesalahan yang terjadi selama proses peresepan obat atau penulisan resep. Dampak dari kesalahan tersebut sangat beragam, mulai yang tidak memberi resiko sama sekali hingga terjadinya kecacatan bahkan kematian (Siti, 2015).

Berdasarkan masalah tersebut, dilakukan pengkajian terhadap kelengkapan administratif pada resep apakah memenuhi ketentuan kelengkapan administratif resep menurut Permenkes No 35 tahun 2014. Penelitian dilakukan di apotek Sthira Dhipa yang berada di wilayah Denpasar Selatan. Pemilihan lokasi penelitian di apotek Sthira Dhipa pada dasarnya karena di apotek Sthira Dhipa melakukan pelayanan terhadap resep dokter sehingga jumlah populasi cukup banyak dalam hal ini resep pasien. Sampel penelitian yang diambil yaitu resep dokter spesialis kandungan yang merupakan resep luar biasa dimana pada resep ibu hamil ada beberapa obat yang kontraindikasi dan dapat memberi resiko bagi kesehatan ibu serta dapat memberi efek yang tidak dikehendaki pada janin selama masa kehamilan. Sampel resep yang diambil yaitu pada bulan Januari-Mei 2015 karena kedatangan pasien pada bulan tersebut merupakan yang terbanyak.

\section{METODE PENELITIAN}

Penelitian ini bersifat deskriptif, yaitu mendeskripsikan secara sistematis, faktual dan akurat terhadap suatu populasi atau daerah-daerah tertentu, mengenai sifat-sifat dan faktor-faktor tertentu (Zainuddin, 1999). Penelitian ini dilakukan dengan melihat resep di apotek, kemudian dicatat pada tabel pengumpulan data.

Jenis data penelitian ini retrospektif, yaitu penelitian yang dilakukan sekarang berdasarkan kumpulan data dari masa lalu (Zainuddin, 1999). Kumpulan data dari masa lalu pada penelitian ini atau sampel adalah resep dokter spesialis kandungan pada bulan Januari-Mei 2015. Penelitian dilakukan di apotek Sthira Dhipa di wilayah Denpasar Selatan. Pemilihan apotek yang digunakan sebagai tempat pengambilan sampel resep dilakukan dengan cara random sampling (Tjokronegoro, 1999).

Pengambilan data dilakukan dengan cara mendatangi Apotek Sthira Dhipa di Wilayah Denpasar Selatan, kemudian peneliti mulai mengamati seluruh resep yang masuk selama periode Januari-Mei 2015 yang ditulis oleh dokter spesialis kandungan. Selanjutnya dilakukan skrining administratif dengan mengisi tabel 
pengambilan data, sesuai dengan aspek kelengkapan resep yang ditinjau. Kemudian data yang di peroleh akan dikumpulkan dan data tersebut disajikan secara deskriptif.

\section{HASIL DAN PEMBAHASAN}

Penelitian ini telah dilaksanakan pada bulan Juni 2015 di Apotek Sthira Dhipa. Pada penelitian jumlah sampel resep yaitu 350 resep. Dengan menghitung persentase dari data tersebut maka hasil persentase kelengkapan administratif dari resep dokter spesialis kandungan bulan Januari - Mei 2015 hasilnya diuraikan maka:

Karakteristik Kelengkapan Resep

a. Kesalahan Identitas Dokter

Tabel 4.1 Kesalahan Identitas Dokter

\begin{tabular}{cccc}
\hline No & $\begin{array}{c}\text { Identitas } \\
\text { Dokter }\end{array}$ & Jumlah & $\begin{array}{c}\text { Persentase } \\
(\%)\end{array}$ \\
\hline $\mathbf{1}$ & SIP Dokter & 350 & 100 \\
\hline
\end{tabular}

b. Kesalahan Penulisan

Tabel 4.2 Kesalahan Penulisan

\begin{tabular}{cccc}
\hline No & Penulisan & Jumlah & $\begin{array}{c}\text { Persentase } \\
(\boldsymbol{\%})\end{array}$ \\
\hline $\mathbf{1}$ & Paraf Dokter & 67 & 19 \\
\hline $\mathbf{2}$ & $\begin{array}{c}\text { Tanggal } \\
\text { Penulisan Resep }\end{array}$ & 5 & 1 \\
\hline
\end{tabular}

c. Kesalahan Identitas Pasien

Tabel 4.3 Kesalahan Identitas Pasien

\begin{tabular}{cccc}
\hline No & $\begin{array}{c}\text { Identitas } \\
\text { Pasien }\end{array}$ & Jumlah & $\begin{array}{c}\text { Persentase } \\
(\mathbf{\%})\end{array}$ \\
\hline $\mathbf{1}$ & Umur Pasien & 217 & 62 \\
\hline $\mathbf{2}$ & Jenis Kelamin & 350 & 100 \\
\hline $\mathbf{3}$ & Berat Badan & 350 & 100 \\
\hline $\mathbf{4}$ & Alamat Pasien & 348 & 99,43 \\
\hline
\end{tabular}

Tabel 4.4 Pengkajian Kelengkapan Administratif Resep di Apotek Sthira Dhipa

\begin{tabular}{|c|c|c|c|c|c|}
\hline \multirow{2}{*}{ NO } & \multirow{2}{*}{$\begin{array}{l}\text { Pengelompokan } \\
\text { Kelengkapan } \\
\text { Administratif }\end{array}$} & \multicolumn{2}{|c|}{$\begin{array}{c}\text { Jumlah } \\
\text { Resep }\end{array}$} & \multicolumn{2}{|c|}{ Persentase } \\
\hline & & Ada & $\begin{array}{c}\text { Tidak } \\
\text { Ada }\end{array}$ & Ada & $\begin{array}{c}\text { Tidak } \\
\text { Ada }\end{array}$ \\
\hline 1 & Nama Pasien & 350 & - & $100 \%$ & - \\
\hline 2 & Umur Pasien & 133 & 217 & $38 \%$ & $62 \%$ \\
\hline 3 & Jenis Kelamin & - & 350 & - & $100 \%$ \\
\hline 4 & Berat Badan & - & 350 & - & $100 \%$ \\
\hline 5 & Nama Dokter & 350 & - & $100 \%$ & - \\
\hline 6 & SIP Dokter & - & 350 & - & $100 \%$ \\
\hline 7 & Alamat Dokter & 350 & - & $100 \%$ & - \\
\hline 8 & Alamat Pasien & 2 & 348 & $0,57 \%$ & $99,43 \%$ \\
\hline 9 & No. Telepon & 350 & - & $100 \%$ & - \\
\hline 10 & Paraf & 283 & 67 & $81 \%$ & $19 \%$ \\
\hline 11 & Tanggal Resep & 345 & 5 & $99 \%$ & $1 \%$ \\
\hline
\end{tabular}

Tabel 4.5 Kelengkapan Administratif Resep secara keseluruhan

\begin{tabular}{ccc}
\hline $\begin{array}{c}\text { Kelengkapan } \\
\text { Administratif Resep }\end{array}$ & Jumlah & Persentase \\
\hline Sesuai & 0 & $0 \%$ \\
\hline Tidak Sesuai & 350 & $100 \%$ \\
\hline
\end{tabular}

Penelitian ini dilakukan untuk mengetahui bagaimana kelengkapan resep secara administratif yang dilakukan terhadap 350 lembar resep di Apotek Sthira Dhipa pada bulan Januari-Mei 2015. Pada pengkajian resep ini digunakan parameter pedoman yaitu Peraturan Menteri Kesehatan Republik Indonesia No. 35 tahun 2014 tentang standar pelayanan kefarmasian di Apotek dimana dilihat kajian resep secara administratif.

Skrining resep merupakan suatu pemeriksaan resep yang pertama kali dilakukan petugas apotek setelah resep diterima. Ada tiga aspek yang perlu diperhatikan dalam skrining resep yakni kelengkapan administratif, kesesuaian farmasetik dan pertimbangan klinis. Pada penelitian ini skrining resep yang dilakukan oleh peneliti hanya berupa skrining kelengkapan administratif resep. Aspek admnistratif resep dipilih karena merupakan skrining awal pada saat resep dilayani di apotek, skrining admnistratif perlu dilakukan karena mencakup seluruh informasi di dalam resep yang berkaitan dengan kejelasaan tulisan obat, keabsahan resep, dan kejelasan informasi di dalam resep. Kajian resep secara administratif merupakan aspek yang sangat penting dalam peresepan karena dapat membantu mengurangi terjadinya medication error. Bentuk medication error yang terjadi adalah pada fase prescribing (error terjadi pada penulisan resep) yaitu kesalahan yang terjadi selama proses peresepan obat atau penulisan resep. Melalui hasil pengamatan dari 350 lembar resep diketahui masih banyak terdapat ketidaklengkapan penulisan resep setiap harinya.

Hasil penelitian menunjukan berdasarkan tabel 4.4 persentase kejadian ketidaklengkapan resep di apotek Sthira Dhipa yaitu umur pasien $62 \%$, jenis kelamin pasien $100 \%$, berat badan pasien $100 \%$, SIP dokter $100 \%$, alamat pasien $99,43 \%$, paraf dokter $19 \%$, serta tanggal resep $1 \%$. Evaluasi tentang kelengkapan administratif resep nama pasien, nama dokter, alamat dokter, serta no telepon dokter yang dituliskan oleh dokter telah mencapai $100 \%$. Dalam hal ini dokter berperan baik dalam proses penyembuhan pasien sehingga tidak berpotensi untuk terjadi medication error.

Penulisan Surat Ijin Praktek (SIP) dokter merupakan unsur yang paling tidak sesuai, dalam resep wajib dicantumkan SIP dokter untuk menjamin keamanan pasien, bahwa dokter yang 
bersangkutan mempunyai hak dan dilindungi undang-undang dalam memberikan pengobatan bagi pasiennya dan telah memenuhi syarat untuk menjalankan praktek seperti yang telah ditetapkan oleh Undang-Undang serta untuk menjamin bahwa dokter tersebut secara sah diakui dalam praktek keprofesian dokter. Peraturan menteri kesehatan juga menyebutkan bahwa dokter, dokter gigi, dan dokter hewan wajib memliki SIP (Surat Ijin Praktek). Namun pada kenyataannya masih banyak dokter spesialis yang tidak mencantumkan SIP dapat dilihat dari resep yang diterima dan dilayani oleh Apotek Sthira Dhipa. Dari hasil penelitian di lapangan menujukan bahwa total ketidaklengkapan SIP dokter ada 350 dari 350 resep atau $100 \%$.

Alamat dokter terdiri dari alamat praktek dan nomor telepon dokter yang biasa dicantumkan dalam resep. Alamat dokter dan nomor telepon harus dicantumkan dengan jelas dan diperlukan karena apabila suatu resep tulisannya tidak jelas atau meragukan bisa langsung menghubungi dokter yang bersangkutan, hal ini juga akan memperlancar pelayanan pasien pada waktu di apotek. Dari hasil penelitian di apotek Sthira Dhipa kelengkapan alamat dokter sebanyak 350 resep dari 350 resep atau sudah $100 \%$.

Pencantuman paraf dokter juga berperan penting dalam resep agar dapat menjamin keaslian resep, berfungsi sebagai legalitas dan keabsahan resep tersebut serta dapat dipertanggung jawabkan agar tidak disalahgunakan di masyarakat umum. Hal ini terkait dalam penulisan resep narkotik maupun psikotropika. Tetapi di lapangan masih banyak kejadian dokter tidak mencantumkan paraf dalam penulisan resep. Terdapat 67 resep mempunyai ketidaklengkapan paraf dokter dari 350 resep atau $19 \%$ kejadian.

Tanggal penulisan resep dicantumkan untuk keamanan pasien dalam hal penggambilan obat. Apoteker dapat menentukan apakah resep tersebut masih bisa dilayani di apotek atau disarankan kembali ke dokter berkaitan dengan kondisi pasien meskipun di Indonesia belum ada ketentuan batas maksimal resep dapat dilayani di apotek. Pencantuman tanggal penulisan resep yang telah dilakukan oleh dokter belum semuanya memenuhi karena masih ada sekitar 5 resep dari 350 resep atau $1 \%$ dari resep yang masuk di apotek tidak menuliskan tanggal peresepan.

Jika ditinjau dari kesalahan identitas pasien, pencantuman nama pasien di dalam resep sangat berguna untuk menghindari tertukarnya obat dengan pasien lain pada waktu pelayanan di apotek. Hasil penelitian menunjukkan bahwa kelengkapan nama pasien yang dicantumkan sudah $100 \%$. Alamat pasien sering kali diabaikan oleh penulis resep (dokter), alamat pasien berguna sebagai identitas pasien apabila terjadi kesalahan dalam pemberian obat di apotek, atau obat tertukar dengan pasien lain serta hal ini sangat diperlukan dalam proses pelayanan peresepan sebagai pembeda ketika ada nama pasien yang sama agar tidak terjadi kesalahan pemberian obat pada pasien. Dari hasil penelitian yang didapatkan sebanyak 348 resep dari total sampel 350 atau $99,43 \%$ kejadian ketidaklengkapan penulisan alamat pasien.

Selain nama pasien data pasien seperti umur pasien dalam penulisan resep cukup penting yang berguna dalam hal perhitungan dosis karena banyak rumus yang digunakan untuk perhitungan dosis dengan menggunakan umur pasien, umur pasien juga berkaitan dengan kesesuaian bentuk sediaan. Terdapat 217 resep dari total 350 sampel yang diambil atau $62 \%$ kejadian ketidaklengkapan pencantuman umur pasien. Umur dalam penulisan resep sangat diperlukan karena untuk dapat mengetahui dosis yang diberikan sudah sesuai atau belum. Apoteker dan petugas apotek mengambil peran dalam penulisan umur dalam selembar resep

Jenis kelamin merupakan salah satu aspek yang diperlukan dalam perencanaan dosis karena dapat mempengaruhi faktor dosis obat pada pasien. Namun dari hasil penelitian tidak ditemukan satu resep yang menuliskan jenis kelamin dari total 350 resep atau sebesar $100 \%$ tidak mencantumkan jenis kelamin pasien, walaupun resep yang diteliti merupakan resep dari dokter spesialis kandungan yang pasiennya tentu wanita.

Dokter tidak menuliskan berat badan dalam peresepan pasien, berat badan juga merupakan salah satu aspek yang diperlukan dalam perhitungan dosis. Dalam penentuan dosis para ahli telah membuat rumus khusus berdasarkan berat badan seseorang, untuk itu berat badan sangat perlu dicantumkan dalam penulisan resep. Dari total 350 resep 100\% resep tidak mencantumkan berat badan pasien padahal berat badan sangat penting dalam perhitungan dosis yang dilakukan apoteker pada saat menyediakan obat. Ada baiknya jika farmasis yang bekerja di apotek untuk membantu melengkapi penulisan berat badan pasien. Dalam penulisan berat badan pasien apoteker dan petugas apotek memberikan bagian lebih dalam melengkapi.

Sebenarnya tugas dari apoteker atau petugas diapotek saat pertama kali menerima resep yaitu melakukan skrining resep dimana memeriksa kelengkapan administratifnya dan apabila terjadi kekurangan dalam resep tersebut bisa ditambahkan oleh apoteker atau petugas di apotek. 


\section{SIMPULAN}

Berdasarkan hasil penelitian kelengkapan resep dokter spesialis kandungan periode JanuariMei 2015 di Apotek Sthira Dhipa belum memenuhi ketentuan kelengkapan administratif resep menurut Permenkes No 35 tahun 2014.

\section{DAFTAR PUSTAKA}

Anonim. 1980. Peraturan Pemerintah No.25 tahun 1980 tentang perubahan atas Peraturan Pemerintah No. 26 tahun 1965 tentang Apotek. Jakarta: Departemen Kesehatan RI.

Anonim. 2004. Keputusan Mentri Kesehatan Republik Indonesia Nomor 1027/Menkes/SK/IX/2004 tentang Standar Pelayanan Kefarmasian di Apotek. Jakarta: Direktorat Jendral Yanfar dan Alkes Depkes RI.

Anief, M. 2000. Ilmu Meracik Obat Teori dan Praktik. Yogyakarta: Gadjah Mada University Press. P. 25.

Anief, M. 2007. Farmasetika. Gadjah Mada University Press. Yogyakarta.

Cahyono, J.B.S.B, 2008. Membangun Budaya Keselamatan Pasien dalam Praktik Kedokteran. Yogyakarta: Kanisius.

Charles J.P, dan Endang Kumolosari. 2006. Farmasi Klinik Teori dan Penerapan. Jakarta: Buku Kedokteran EGC

Darmawan, Rizky. 2014. Skripsi: Analisis Kelengkapan Administrasi dan Potensial Interaksi Pada Resep Racikan di Lima
Apotek Kota Surakarta Tahun 2012. Surakarta: Universitas Muhamadiyah Surakarta

Jas, A. 2009. Perihal Resep \& Dosis serta Latihan Menulis Resep Edisi 12. Medan: Universitas Sumatera Utara Press.

Menkes RI. 1981. Keputusan Menteri Kesehatan RI Nomor 278/MENKES/SK/V/1981 tentang Persyaratan Apotek. Jakarta: Departemen Kesehatan RI.

Menkes RI. 2014. Peraturan Menteri Kesehatan Republik Indonesia Nomor 35 Tahun 2014 Tentang Standar Pelayanan Kefarmasian Di Apotek. Jakarta: Departemen Kesehatan RI.

Riyanto, A. 2011. Aplikasi Metodologi Penelitian Kesehatan. Yogyakarta: Nuha Medika.

Siregar, 2004. Farmasi Rumah Sakit Teori dan Penerapan. Jakarta: Penerbit Buku Kedokteran EGC.

Siti, 2015. Skripsi: Kajian Administratif, Farmasetik dan Klinis Resep Pasien Rawat Jalan di Rumkital Dr. Mintohardjo pada bulan Januari 2015. Jakarta

Tjokronegoro, A., 1999. Metodologi Penelitian. Surabaya: Airlangga University Press, hal. $35-36$

Wibowo, A. 2010. Skripsi: Analisis Kelengkapan Resep di Apotek Wilayah Lamongan Bulan Februari 2010. Surabaya.

Zainuddin., 1999. Metode Penelitian. Surabaya: Airlangga University Press. 